\title{
Learning Power Conditioning Basics at the Technical Engineering School of Barcelona (EUETIB/UPC)
}

\author{
Jordi de la Hoz, Sergi Fillet, Alfredo de Blas \\ Department of Electrical Engineering \\ E.U.E.T.I.B., Politechnical University of Catalonia \\ Compte d'Urgell, 187, 08036 Barcelona (Spain) \\ phone:+34 934137319, fax:+34 934137401, e-mail: jordi.de.la.hoz@upc.es, Sergi.fillet@upc.es, \\ alfredo.de.blas@upc.es
}

\begin{abstract}
Power quality, as a new important target on power system design, is becoming fundamental on engineers curricula. In order to introduce basic concepts, it has been decided to create an introductory course opened to all the technical engineering students.

The main objectives of the course "Power systems conditioning applications" are to allow engineering students to learn fundamentals and essentials on power quality and systems conditioning.

Cause the diverse student's formation, a novel methodology, Project Based Learning based, is being developed.
\end{abstract}

\section{Key words:}

Project Based Learning, Study Group Work, Power Quality.

\section{Introduction}

Power electronics has become an essential part of industrial applications. Their impact on networks and utilities is being considered in several ways. Sensibility of controlled-speed-devices, high efficiency actuators,... have incremented impact on energy quality and reliability.

Uncontrolled and untimely triggering of utility protections, as circuit breakers, thermal-magnetic breakers,... cause industrial processes interruptions and their consequent high economical losses. On the other side, an increasing interest on power efficiency and environmental factors have increased pressure to find ways to increase utilities efficiency.

Although the increasing importance of this kind of effects, a low presence on actual curricula has been detected. To mitigate that important absence, it's been decided to develop a novel course on "Power system conditioning applications".

That course is designed to introduce basic concepts; and it has been decided to remain opened to all the technical engineering students as an optional subject. As an indirect effect of this decision, the students arrive with multiple and diverse formation, frequently without basic required electrical knowledge.

The different original specialties of students are, at first sight, an important impediment to develop an specific course like this one. Nevertheless it has been tried to make the most of the fact. A Project Based Learning method, considered to be more suitable, is being developed.

\section{Course antecedents}

This course was initially developed on spring, 2003, using traditional methodology, based on expositive sessions and computer-based simulation reinforcement. This course, due to their optional character, is provided with 4,5 credits, corresponding to $2 \mathrm{~h} /$ week of expositive sessions and $2 \mathrm{~h}$ every 2 weeks of computer-simulation based. Once the time was distributed among evaluation, introductory and ordinal time, a working time of $26 \mathrm{~h}$ dedicated to expositive sessions and $12 \mathrm{~h}$ dedicated to simulation was considered.

On the 26 hours dedicated to expositive sessions, it was tried to reach the point from where, students would be able to take a global but though vision of the basic problems and solutions. In order to obtain these results, this items structure was taken:

- Basic electrical and mathematical concepts used on the field were introduced to equalize theoretical knowledge of students. Examples of electrical concepts are a brief introduction to power systems modelazitation and determination of model parameters on electrical systems. As an example of mathematical concepts (applied to electricity), an extensive introduction to electrical coordinates (Park, Fortesquieu), their use and applications was done.

- With a supposed homogeneous level reached, an study of electrical systems utilities components and particularities was developed. This study was done in two times, considering the grid utility and user utility as two conceptually different systems. Grid utility was studied with a special consideration on how electrical disturbances are produced and transmitted. User utility was studied centering on perturbation 
generators and power quality susceptible devices.

- Supposing basic knowledge of elements constituting power systems, it was proceeded to systematize electrical disturbances, their causes, their effects and their typical measurement parameters. Special emphasis on economical cost of most frequent, like surges and harmonics, and considerations over power quality and industrial efficiency was taken in order to obtain a global vision of power quality impact.

- When importance of power quality was theoretically assumed, a brief introduction on power quality correction methods, like filtering, was done. Basic elements used to compensate disturbances, like UPS, active and passive filters, power factor compensators,... were introduced.

- Trying to give them basic comprehension of composition and behavior of the introduced devices, theoretic tools were done. As examples, basic inverter structures, centering on Voltage Source Inverters and Current Source Inverters, their basic design criteria and control was introduced. High and medium power semiconductor devices were introduced, centering on comparative selection criteria.

- To finalize this basic overview, principal flexible AC transport systems were described. With this introduction to concepts like static compensators, power flow, ACvsDC transmission... a general vision on power electronics impacts on utilities was closed.

On the 12 hours dedicated to computer-based simulation reinforcement, it was tried to provide students with software tools to give a concrete vision of the mathematical and theoretical electrical tools explained on the expositive sessions. In order to obtain these results, this items structure was taken:

- Matlab-simulink ${ }^{\circledR}$ was introduced as an powerful tool to integrate complicated calculation with electrical system modeling. Cause students didn't know program operation and basic concepts of block systems simulation related with simulink, and extensive introduction was necessary.

- When the platform was friendly for them, the tool-boxes used to control and simulate electrical systems were explained. Measurements and stability concepts were given using simulation.

- Using control and mathematical tool-boxes over balanced and unbalanced systems, park coordinates, homopolar effects, harmonics,... were described, used and experimented virtually.

- The results of the different student groups were exposed orally to evaluate the accumulated knowledge.

During course implantation it was detected that students didn't reach objectives sufficiently. In order to mitigate problems detected, it was considered necessary to adaptate difficulty level to students. The same target objectives were explained in an easy level for them.

As examples of these adaptations, initially, it was considered to explain how affects unbalanced parameters to utilities park-models and appearance of undesirable current components. Due to the inherent difficulty of that kind of concepts, finally it was decided to go deeply only on relation among park components and unbalanced components. Similar cases were found on most of the objectives planed.

At the end of the course implementation, and after student's opinions were collected, a deeper evaluation of course results was considered necessary. The unsatisfactory results obtained, carried us to a objectives and methodology reconsideration. The analysis of those results revealed not only that objectives were too much ambitious, even methodology was inappropriate.

\section{Course Objectives}

Basic course objectives were maintained the same, redefining concrete objectives to create four principal areas. Those main objectives of the course "Power systems conditioning applications" are defined as "allow engineering students to learn fundamentals and essentials on power quality and systems conditioning".

In order to achieve the main course objectives, 4 secondary objective areas are defined:

1. Basic Principles and Elements of Utilities: Due to the diverse curricula of students, basic electrical installations concepts can't be assumed. A basic comprehension of fundamental concepts related to electrical installations has to be assumed by the student.

2. Power Quality Phenomena and Parameters: The students have to be able to identify typical power quality disturbances, their causes and their principal effects.

3. Principles in Power Quality Conditioning: In order to mitigate power quality disturbances, the student almost has to identify what principles reside behind power quality conditioning solutions.

4. Commercial Devices: As a final target, an overall vision of power quality commercial devices available is expected.

Basic Principles and Elements of Utilities: The specific objectives of that area are:

- Students must obtain a general vision of typical electric utilities. They must be able to describe different utility parts like protections, distribution boards, load types...

- Students must know basic function principles of most important loads.

- Students must be able to identify the different electrical protection devices, their basic function and their working principles.

- Basic legislation will be introduced in order to contextualize legal constrictions to electrical installations. 
Power Quality Phenomena and Parameters: The specific objectives of that area are:

- Students must be able to identify most common perturbation sources and what kind of disturbances they introduce.

- Students must be able to identify most common perturbation sensible devices and what kind of disturbances are they sensible to.

- Students should be able to identify basic perturbations produced and weaknesses on composed loads.

- Students must know about most common problems in electrical utilities, and their typical measurement parameters.

Principles in Power Quality Conditioning: The specific objectives of that area are:

- Students must be familiar with basic mathematical and electrical principles related to power quality conditioning, like park components, common mode current, unbalanced components...

- $\quad$ Student must know basic application principles used on power quality conditioning, like current and voltage harmonics filtering, uninterruptible power systems, power factor correction...

- Student must be able to understand basic electrical and electronic topologies applied on power quality conditioning, like current and voltage harmonic filter topologies, inverter topologies...

- Students must know about basic principles related to control of the previous topologies in order to obtain the desired behavior.

Commercial Devices: The specific objectives of that area are:

- Students must obtain an overall vision of power quality commercial devices available.

- Students must select an power quality commercial application, understand their specifications, and evaluate their functionality related to the course topics.

\section{Pedagogical Methodology}

In order to choose pedagogical methodology, three factors have been taken into consideration:

- An excessive students passivity was detected. The traditional methodology used in the first course implementation didn't create favorable conditions to student participation. Only the students more motivated with the course objectives reach an acceptable level of objectives. The erroneous conception of a course not associated with the basic engineering curricula increases student expectative on lowwork related with the course.

- The different original specialties of students are, at first sight, an important impediment to develop a specific course like this one. An individual work can't be assumed to be enough to obtain desired objectives but different profiles must be used to take advantage on team working.

- Due to an extensive interest on course, a modulus of 24 students must be considered.

With these considerations, it was assumed that a team work and active participation must be obtained. Team Works related with the basic areas, where students must achieve specific objectives and prove it in an oral exposition is chose.

The 24 students are divided in 6 work teams. After a work time related with every area, each team must expose their work to another team, that team, randomly chose, must be, in combination with teacher, of exposing team evaluation. When the process is finished, every group must have made a public exposition and evaluate another. In order to develop team work abilities and self-learning, an opened methodology, where students are provided with basic information and are responsible of their work planning and search of necessary information under teacher supervision.

\section{Conclusion}

The methodology explained in this contribution, is expected to be an appropriated one in order to approximate electrical concepts to non-electrical students in a more efficient way.

The sub-group and personalized work, typical of the exposed methodology, can be assumed as one of the best choices to adjust a course to students with different interests and backgrounds.

As additional results non-technical attitudes and aptitudes required in their future careers are expected to be developed.

\section{References}

[1]. Kehoe, C.; Guzdial, M.; Turns, J.; "What we know about technological support for project-based learning" in Frontiers in Education Conference, Vol.2, pp. $918-922$

[2]. Mofty, A.; Youssef, K.; "Industrial power quality problems " in CIRED. 16th International Conference and Exhibition on, Volume: 2

[3]. Tillis, L.S.; Williams, C.W., Jr.; "Voltage sag investigation and mitigation in an electronics manufacturing plant", Southcon/94. Conference Record, 29-31 March 1994 Page(s): 378 -381

[4]. S.J.; Radmer, D.T.; Montgomery, R.; Chen, J.; Foertsch, J.S.; "Harmonic compensation of commercial and industrial power systems" Dodroe, Transmission and Distribution Conference, 1994., Proceedings of the 1994 IEEE Power Engineering Society, 10-15 April 1994 Page(s): 97 -102 